\title{
The reproducibility and sensitivity of sural nerve morphometry in the assessment of diabetic peripheral polyneuropathy
}

\author{
A. A.F. Sima ${ }^{1}$, M. B. Brown ${ }^{1}$, A.Prashar ${ }^{2}$, S. Chakrabarti ${ }^{2}$ C. Laudadio $^{3}$ and D. A. Greene $^{1}$ \\ ${ }^{1}$ Departments of Pathology, Biostatistics and Internal Medicine, and the Michigan Diabetes Research and Training Center, University of \\ Michigan, Ann Arbor, Michigan, USA ${ }^{2}$ Department of Pathology, University of Manitoba, Winnipeg, Manitoba, Canada \\ ${ }^{3}$ School of Life and Health Sciences, University of Delaware, Newark, Delaware, USA
}

\begin{abstract}
Summary. The nerve fibre loss, atrophy and injury of diabetic peripheral polyneuropathy and their responses to metabolic intervention have been studied by morphometric analysis of sural nerve biopsies. The magnitudes and sources of intraand inter-individual variation in these morphometric measures have not been investigated previously in a systematic manner. Morphometric parameters of nerve fibre damage were measured in four separate fascicles from bilateral sural nerve specimens obtained post-mortem from 13 diabetic and 13 non-diabetic subjects. Intra- and inter-individual coefficients of variation were computed and com-
\end{abstract}

pared to the magnitude of the differences between normal and diabetic subjects. Several morphometric variables emerged as highly sensitive and reproducible measures of nerve fibre damage suitable for clinical studies of diabetic peripheral polyneuropathy. These observations provide a rational basis for the design of future clinical trials employing morphometric end-points.

Key words: Diabetes mellitus, neuropathy, morphometry, sural nerve.
Diabetic peripheral polyneuropathy is a disease of progressive nerve fibre loss, atrophy and injury clinically manifest as deteriorating neural function with or without accompanying dysaesthetic or paraesthetic symptoms. The disease culminates in severe tertiary complications, such as insensitivity to pain, anaesthesia, limb deformity, ulceration, neuroarthropathy, infection and amputation [1]. While sensory loss corresponds with the degree of nerve fibre pathology [2], neuropathic symptoms are unreliable indicators of nerve fibre injury [3] and tend to be highly varied, transient, and difficult to quantify. Symptoms such as pain appear to reflect processes independent of the progressive nerve fibre damage, such as fibre regeneration [3] or mechanical foot deformities. Neuropsychological measurements of sensory loss remain difficult to standardize and possess wide day-to-day variation [4, 5]. Electrophysiological tests such as waveform analysis of the evoked muscle or nerve potentials, micro-neurography or single-fibre electromyography [6], that accurately reflect the functional integrity of nerve fibre populations, are not widely available and remain incompletely standardized. Readily available, well-standardized diagnostic nerve conduction tests are highly reproducible, but their direct translation to nerve fibre damage remains incompletely established $[1,7]$. Ironically, the brisk responsiveness of these standard tests to abrupt alteration in glu- cose control has clouded their morphological and clinical interpretability. For example, the small improvements in nerve conduction velocity following enhanced glucose control [8-15] or administration of an aldose reductase inhibitor (ARI) [16] have been dismissed as reflecting changes in nerve biochemistry and/or hydration $[17,18]$. Therefore, methods that unequivocally quantitate nerve fibre damage in diabetic neuropathy are essential to define its natural history, pathophysiology, and therapeutic responses, and to develop surrogate measures for clinical assessment.

Sural nerve biopsy is a well-established, safe, although invasive diagnostic technique that has been applied in clinical trials to morphometrically quantify nerve fibre damage of diabetic neuropathy $[7,19-21]$. The myelinated nerve fibre loss, atrophy and injury of diabetic neuropathy can be quantified by a combination of light-microscopic morphometric assessment ("light morphometry"), categorization of teased myelinated nerve fibres ("teased fibre analysis"), and by quantitative electron-microscopic analysis of the nodal and internodal architecture of myelinated nerve fibers ("EM morphometry") [21]. Automated, computer-driven light morphometry provides measures of myelinated fibre density (the number of myelinated fibres per unit cross-sectional area), mean myelinated fibre size, and myelinated fibre occupancy 
(the percentage of total fascicular area comprised of myelinated fibres). Individually teased nerve fibres are categorized into one of eight well-defined groupings, and expressed as percents: normal fibres ("\% normal"), or fibres exhibiting nodal swelling ("\% swelling"), paranodal demyelination ("\% demyelination"), paranodal remyelination (so-called "intercalated nodes") ("\% intercalated"), segmental demyelination ("\% segmental"), excessive myelin wrinkling ("\% wrinkled"), Wallerian degeneration ("\% Wallerian"), or remyelination/regeneration ("\% regenerated") [21]. The percents calculated for all but \% regenerated exclude regenerated fibres so that they would not dilute the percentages in other categories. EM morphometry quantitates an ultrastructural lesion of the node of Ranvier found in human [21] and animal [22, 23] diabetes, "axo-glial dysjunction" (the loss of the junctional complexes between terminal myelin loops and the axolemma that maintain the structural and functional integrity of the nodal apparatus [24]) ("\% axo-glial"); this lesion appears to be a major determinant of nerve conduction slowing in diabetic rats [24] and patients [25].

In patients with diabetic polyneuropathy, many of these parameters are related to duration and/or type of diabetes and/or the age of the patient [21], and correlate with clinical and electrophysiological responses to metabolic treatment [26]. Nerve morphometry has exhibited greater sensitivity and specificity in the neural response to ARI therapy than conventionally employed electrophysiological, neuropsychological or clinical measures [27, 28]. Highly specific evidence of nerve fibre repair and regeneration and reversal of axonal atrophy were observed in neuropathic patients in response to an ARI $[25,26]$. Moreover, based on longitudinal and cross-sectional data, these parameters appear to account for a major component of the electrophysiological impairment and treatment-responses in diabetic peripheral polyneuropathy $[20,21]$. Thus, improvement in clinically relevant morphometric parameters in sural nerve biopsies could be considered prima facie evidence of efficacy in the treatment of diabetic neuropathy. Despite these encouraging initial applications of quantitative morphometry to clinical trials, the design of future clinical studies with morphometric primary end-points requires formal evaluation of the within-subject and between-subject variability of these morphometric measures, which is the purpose of this communication.

\section{Subjects and methods}

To study the reproducibility and sensitivity of the morphometric measures of nerve fibre damage in diabetes, four sural nerve fascicles (two from the left leg and two from the right leg) were taken within $6 \mathrm{~h}$ of death from each of 26 subjects, 13 diabetic individuals unselected for neuropathy status, and 13 non-diabetic individuals free of diseases associated with peripheral neuropathy. The reproducibility of each of these nerve parameters was assessed by examining the variability within and among individuals with diabetes (patients) and without diabetes (control subjects). Sensitivity was assessed by comparing the within- and between-individual variability of these parameters in the diabetic patients and in control subjects with the group differences of these parameters between diabetic pa- tients and control subjects. The stability of each nerve parameter to post-mortem artifact was assessed by comparing three nerve biopsies obtained premortem from living eadaver donors kept on life support systems with the contralateral sural nerve obtained from the same individuals at autopsy $6 \mathrm{~h}$ after death.

\section{Patient material}

Thirteen consecutive diabetic patients undergoing autopsy at the Health Sciences Center in Winnipeg, Manitoba between October 1987 and June 1988 were included in the study. These nine diabetic males and four diabetic females had a mean age of $52.7 \pm 12.5$ years (range 29-64 years), and included six subjects who had been diagnosed as having Type 1 (insulin-dependent) diabetes mellitus and seven diagnosed as having Type 2 (non-insulin-dependent) diabetes mellitus. Five patients had a recorded clinical diagnosis of diabetic neuropathy (four Type 1 and one Type 2) for a mean duration of $5.4 \pm 2.6$ years (range $1-11$ years). Thirteen non-diabetic control subjects undergoing autopsy during the same period, eight males and five females with a similar mean age of $56.8 \pm 20.0$ years (range 24-81 years) were selected as control subjects. All clinical records were scrutinized to exclude patients with disorders or conditions other than diabetes associated with peripheral neuropathy. Causes of death for diabetic subjects were: seven from cardiovascular disease, two from bronchopneumonia, one each from ruptured berry aneurysm, peritonitis, ruptured aortic aneurysm, and the sequelae from a motor vehicle accident; and for control subjects were: six from cardiovascular disease, four from bronchopneumonia, and one each from intracerebral haemorrhage, cerebral infarction, and gun shot wound. Additionally, three organ-donor subjects whose sural nerves were part of a previously-reported series of non-diabetic control post-mortem biopsies [21] had had their contralateral sural nerves biopsied pre-mortem during organ donation, which were analysed to detect post-mortem changes in morphometric parameters of peripheral nerve.

\section{Biopsy preparation}

In order to avoid mechanical artifacts, each fascicular sural nerve biopsy measuring $-3 \mathrm{~cm}$ in length was carefully dissected and excised from the area posterior to the lateral malleolus, and bisected cross-sectionally with crossed razor blades. The two halves were immediately fixed in $0.1 \mathrm{~mol} / \mathrm{l}$ cacodylate-buffered (pH 7.4) $2.5 \%$ gluteraldehyde for $24 \mathrm{~h}$ at $4^{\circ} \mathrm{C}$, post-fixed for $2 \mathrm{~h}$ at $4^{\circ} \mathrm{C}$ in $0.1 \mathrm{~mol} / \mathrm{l}$ cacodylate-buffered osmium tetroxide ( $\mathrm{pH} 7.4)$, and dehydrated in graded concentrations of alcohol. One specimen was embedded in Epon and semi-thin $(0.5 \mu \mathrm{m})$ cross-sections were cut and stained with toluidine blue for light microscopic morphometry, and ultrathin cross-and longitudinal-sections were cut and stained with aqueous uranyl acetate and lead citrate for EM morphometry. The other specimen was used for teased fibre preparation in unpolymerized Epon. The Epon was polymerized after the teased fibres were prepared so that individually teased fibres could subsequently be examined ultrastructurally.

\section{Microscopic analysis}

Myelinated nerve fibre damage was quantitated by three microscopic techniques; light microscopic morphometry of semi-thin cross sections of nerve fascicles; electronmicroscopic (EM) examination of cross- and longitudinally-sectioned nerve fascicles; and light microscopic scoring of single teased nerve fibres. Images for light morphometry were digitized and processed with a Cambridge Quantamet 10 image analysis system (Olympus Optical Canada Ltd., Montreal, Quebec, Canada). Mean myelinated fibre size was calculated from an image projected through a $100 \times$ lens to a TV monitor and edited to separate abutting myelinated fibres. The number and cross-sectional area (including the myelin sheath) of all 


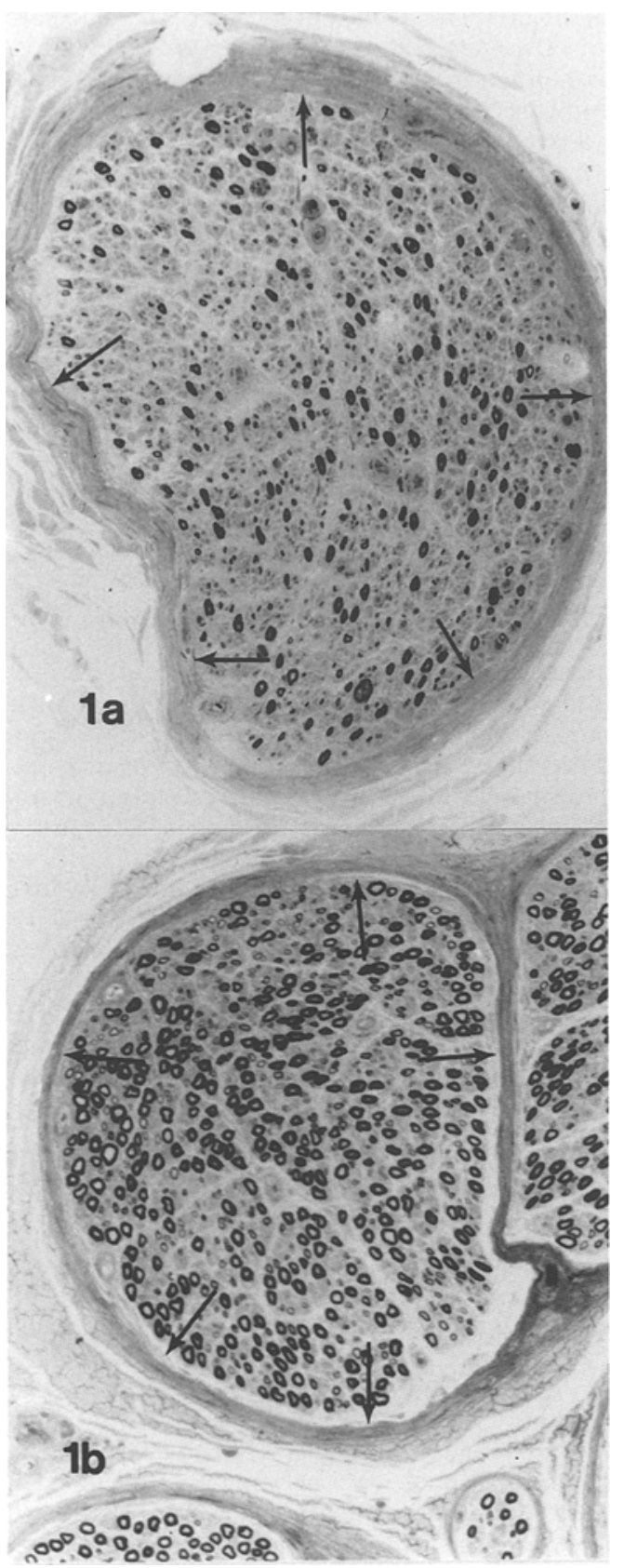

Fig.1 a,b. Representative light-microscopic semi-thin cross-sections of sural nerve fascicles from diabetic (a) and non-diabetic (b) subjects. The number and cross-sectional area of all myelinated fibers within the endoneurial area delineated by the innermost perineurial lamina (arrows) were calculated. From these calculations, myelinated fibre density $\left(\# / \mathrm{mm}^{2}\right)$ and fibre occupancy $(\%)$ were computed. Magnification $145 \times$

myelinated fibres in each fascicle were digitized from consecutive frames covering the entire fascicular cross section. The endoneurial area contained within the innermost perineurial lamella was calculated from an image projected by a $4 \times$ lens. From these calculations the myelinated fibre density $\left(\# / \mathrm{mm}^{2}\right)$ was computed by dividing the fibre number by the fascicular area. Myelinated fibre occupancy was expressed as the fraction (\%) of the endoneurial area occupied by myelinated fibres (Fig.1).

Interfaces between the terminal myelin loops and the paranodal axolemma were examined ultrastructurally for the presence of axoglial junctions in longitudinal ultra-thin sections cut serially through

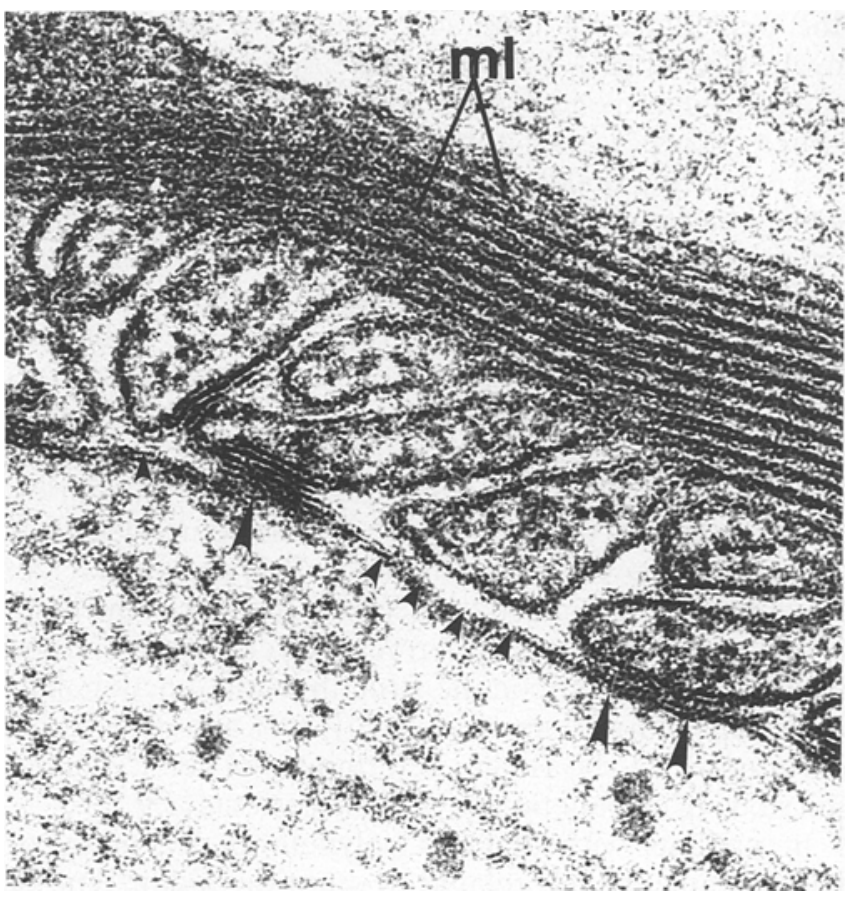

Fig. 2. Electron micrograph of a node of Ranvier exhibiting axo-glial dysjunction. Electronmicroscopic morphometry was employed to assess axo-glial dysjunction, expressed as the percentage of terminal myelin loops devoid of axo-glial junction (\% axo-glial). From each serial ultra-thin section through the paranodal region, only interfaces between the axolemma and the terminal myelin loops displaying clearly visible membranous structure were evaluated. Of these, myelin loops devoid of axo-glial junctions (small arrowheads) were calculated and expressed as a percentage of total myelin loops. The presence of axo-glial junctions between the axolemma and myelin loops are indicated by large arrowheads. $\mathrm{ml}=$ myelin lamellae. Mag: $\times 157,000$

the nerve fibre in the region of the node of Ranvier. Only interfaces in which the axolemma and the terminal myelin loop were both perpendicular to the plane of the section and thus visible as well-defined trilamellar membrane structures were examined (Fig.2). Several serial sections were analysed in order to score each myelin-loop-axolemmal interface in a given node only once for the presence or absence of axo-glial junction. Axo-glial junctions were defined as discrete electron-dense structures $\sim 150 \AA$ in thickness bridging the intercellular space between the terminal myelin loops and the axolemma in the paranodal region $[21,22,25]$. The percentage of axoglial dysjunction ("\% axo-glial") was defined as the percentage of myelin loops devoid of axoglial junctions. In each fascicle a mean of $24.2 \pm 0.6(\mathrm{SEM})$ paranodal regions with a mean total of $421 \pm$ 36 (SEM) terminal myelin loops were examined for the absence of axo-glial junctions.

The frequency of myelinated fibres exhibiting defined structural abnormalities was determined by screening approximately 100 individually teased myelinated fibres per fascicle. Representative random sampling of fibres was assured by sequentially bisecting the fascicle in halves, quarters and eights before teasing out single fibres from each division. Fibres were teased free of adjacent fibres and connective tissue for a length of at least $4-5 \mathrm{~mm}$. An average of $98 \pm 2$ (SEM) fibres were isolated and examined from each fascicle. Each fibre was qualitatively assigned to one of eight well-defined categories $(\mathrm{A}-\mathrm{H})$ based on the presence of characteristic structural features, and the frequency of each type expressed as percent of nonregenerating fibres examined: A: structurally normal fibres ("\% normal") (Fig. 3a); B: paranodal swelling ("\% swelling") defined as a paranodal diameter equal to or greater than $150 \%$ of the 


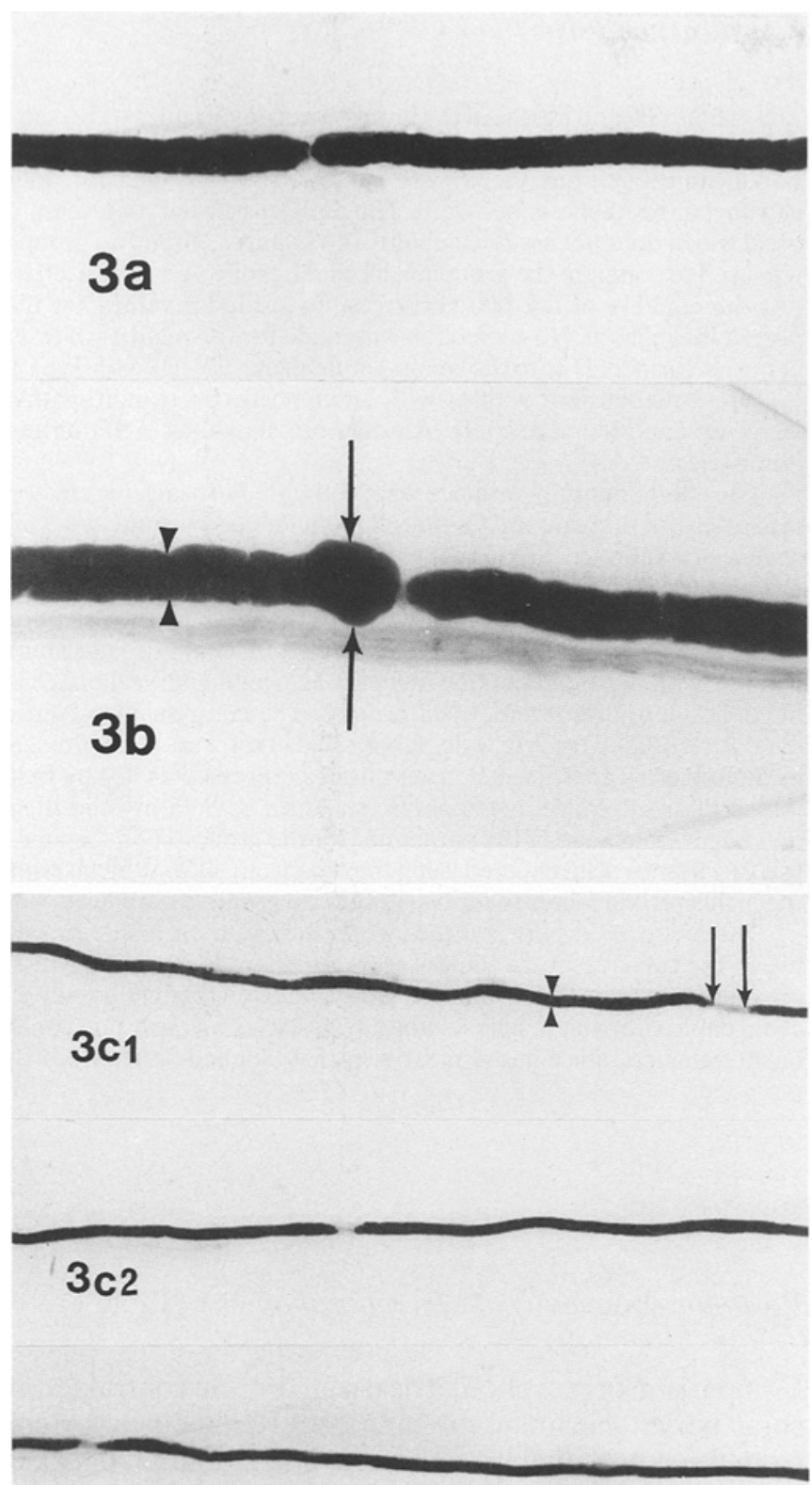

$3 \mathrm{c3}$

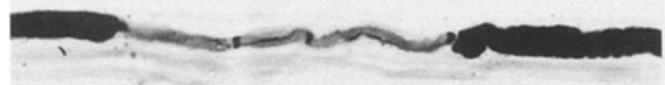

3d

internodal diameter (Fig. 3b); C: paranodal demyelination ("\% demyelination"), defined as a nodal gap equal to or greater in distance than the internodal diameter (Fig. 3c); D: excessive myelin wrinkling ("\% wrinkled"), defined as intact but "corrugated" internodal myelin with great variations in diameter whereby the smallest diameter is equal to or less than $50 \%$ of the greatest diameter (Fig. 4a); E: intercalated (remyelinated) nodes, ("\% intercalated"), characterized by a short and thinly myelinated segment intercalated between two normal internodal segments (Fig.3d);
Fig.3a-d. Teased myelinated fibres exhibiting normal structural appearance (a) or abnormalities of the node of Ranvier $(\mathbf{b}-\mathbf{d})$. Teased fibre analysis was employed to assess the frequency of specific microscopically detectable myelinated fibre abnormalities affecting the node of Ranvier and the internodal segment. The percentage of all teased myelinated fibres exhibiting normal internodal segments and normal nodes of Ranvier (a) was computed and expressed as \% normal. Sequential abnormalities of the node of Ranvier were grouped as either paranodal/nodal swelling (\% swelling) (b) when the paranodal fibre diameter (arrows) was $\geq 150 \%$ of the internodal diameter (arrowheads); as paranodal demyelination (\% demyelination) ( $\mathbf{c}_{1-3}$ ) when the length of the nodal gap (between arrows in $\mathbf{c}_{1}$ ) was $\geq$ the fibre diameter (arrowheads); or as remyelinated (intercalated) nodes (\% intercalated) characterized by short, thinly-myelinated internodes intercalated between two normal internodes (d). The same type of nodal change was often encountered in subsequent nodes of the same fibre e.g. paranodal demyelination in $\mathbf{c}_{2-3}$

F: Wallerian degeneration ("\% Wallerian"), characterized by fragmentation of the myelinated fibre into myelin ovoids and balls in several consecutive internodes (Fig. 4b); G: segmental demyelination ("\% segmental"), defined as fragmentation of myelin within one or more internodal segments (Fig. 4c); $\mathrm{H}$ : regenerated and/or remyelinated fibres, ("\% regenerated"), characterized by short thinly myelinated consecutive internodes and defined as having an internodal length equal to or shorter than $50 \%$ of that which would be expected for fibre diameter (Fig. 4d). Fibres exhibiting more than one abnormality were scored according to the most severe change (with $\mathrm{B}<\mathrm{C}<\mathrm{E}<\mathrm{D}<\mathrm{G}<\mathrm{F}$ ) except for regenerated fibres $(\mathrm{H})$ which were interpreted to reflect a reparative state. The fibres classified $\mathrm{A}-\mathrm{G}$ were expressed as a percentage of total nonregenerated fibres $(\mathrm{A}+\mathrm{B}+\mathrm{C}+\mathrm{D}+\mathrm{E}+\mathrm{F}+\mathrm{G}=100 \%)$ to eliminate a possible dilutional effect of newly-regenerated fibres on the frequency of otherwise normal or abnormal fibres $[21,25,26]$. This adjustment becomes quantitatively important in studies of diabetic neuropathy that include treated patients with active regeneration [26]. For the regenerated fibres, the percent was computed from the total number of fibres including regenerated fibres $[25$, $26]$.

The nerve fibre damage from diabetes identified by these individual morphometric measures was aggregated into three components, fibre loss, atrophy and fibre injury. Fibre loss was defined by the measurement of fibre density (\# fibres $/ \mathrm{mm}^{2}$ ) which remains relatively independent of normal variation in fascicular number and size and level of branching in human sural nerve. Fibre atrophy was assessed by \% wrinkled which correlates closely with the more direct measures of nerve fibre atrophy such as myelin/axon ratio and internodal-length:fibre diameter ratio [25] support this approach. Fibre injury was assessed by \% normal, (a measure of uninjured fibres) and $\%$ swelling, \% demyelination, $\%$ intercalated, $\%$ segmental, and $\%$ Wallerian. Based on these considerations, an index of normality was computed as the product of the percent normal fibres and fibre density, since this index would represent the number or density of structurally normal nerve fibres. This composite index of normality reflects nerve fibre loss (the reduction in fibre density), atrophy (the reduction in \% normal due to the increase in \% wrinkled), and injury (the reduction in \% normal accounted for by changes in \% swelling, $\%$ demyelinated, \% intercalated, \% Wallerian or \% segmental) as well as recording the density or number of structurally normal nerve fibres at the light microscopic level. Regenerative activity was assessed as \% regenerated [21]. Because the subjects in this study were not undergoing treatment to increase fibre regeneration, mean fibre size was considered to be a combined measurement of fibre atrophy and/or the selective loss of larger nerve fibres [21] (in contradistinction to patients undergoing a metabolic intervention associated with increased fibre regeneration, since newly-regenerated fibres are smaller than the fibres that they have replaced [26]). 


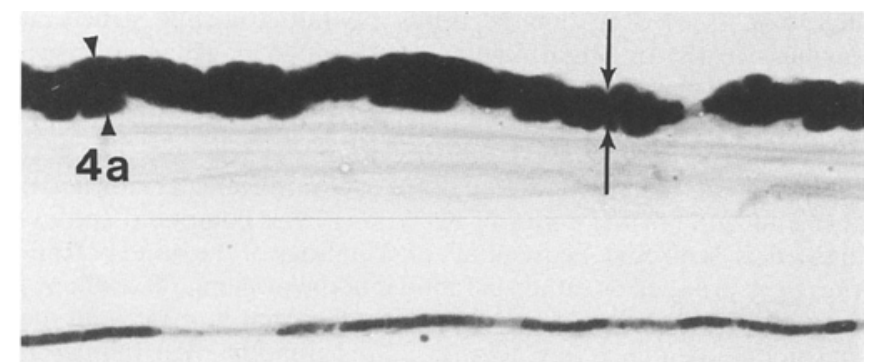

4b1

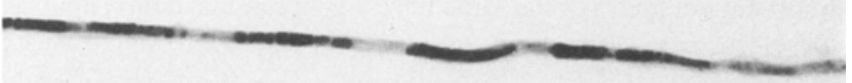

4b2

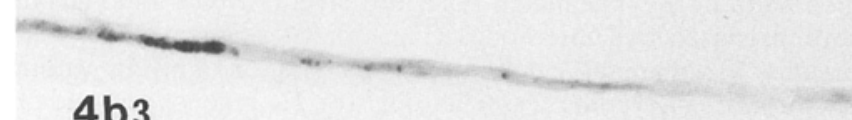

4b3
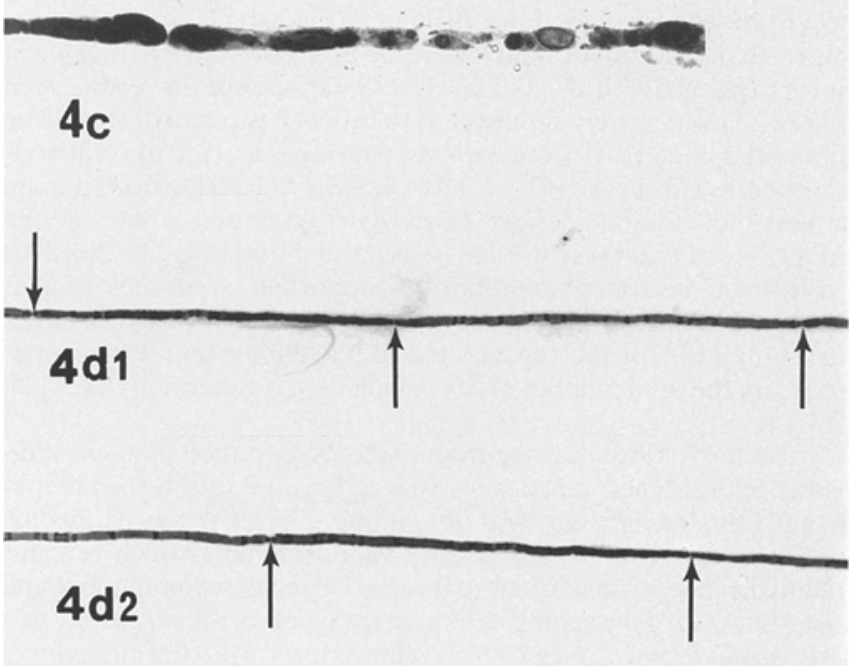

Fig.4a-d. Teased myelinated fibres exhibiting abnormal internodal structure. Teased fibre analysis was employed to assess the frequency of specific abnormalities of the internode, such as excessive myelin wrinkling (\% wrinkled) (a), indicative of axonal atrophy appearing as corrugated "wrinkled" myelin sheaths such that the smallest fibre diameter (arrows) is $\leq 50 \%$ of the greatest diameter (arrowheads). Wallerian degeneration (\% Wallerian) $\left(\mathbf{b}_{1-3}\right)$ is characterized by myelin fragmentation in consecutive internodes. Segmental demyelination (\% segmental) (c) is characterized by demyelination within the internodal segment in contrast to paranodal demyelination (compare with Figure $\mathbf{3} \mathbf{c}_{1-3}$ ). Regenerated fibres (\% regenerated) ( $\mathbf{d}_{1-2}$ ) display short evenly-spaced consecutive internodes (between arrows) with an internodal length $\leq 50 \%$ of that expected for the fibre diameter

\section{Statistical analysis}

The means, SD and ranges of the morphometric variables were computed separately for the diabetic and for the non-diabetic subjects. For technical reasons there were values for \% axo-glial for only eleven of the diabetic subjects. The Behrens-Fisher two-sample $t$-test which does not assume equality of variances of the two groups was used to compare the group means and Levene's test was used to test the equality of the two variances. Two-sided $p$-values are reported throughout. No correction was made for the number of tests being performed. Due to the small sample sizes, subjects with Type 1 or Type 2 diabetes, or with or without clinically-overt neuropathy, were not analysed separately. All data are shown as $\frac{ \pm}{ \pm}$ SD unless otherwise noted.

The components of variance were estimated for each parameter separately for diabetic and for non-diabetic subjects using a two-way analysis-of-variance (ANOVA) with fascicle (two per side) and side (left vs right leg) as factors. In this case non-significance would indicate that there was no systemic difference between the two fascicles on the same side or between the two sides, and would be consistent with the widely-held belief that diabetes-associated nerve damage is in general a diffuse symmetrical process. The components of variance attributed to fascicle, side, subject and error were re-expressed in the tables as coefficients of variations (expressed as \%) by first taking their square roots (to obtain standard deviations) and then dividing by the mean of the parameter for the group. Then the analysis of variance was repeated using the data from all 26 subjects with the inclusion of a factor to represent the two groups of subjects.

The association between the two fascicles on each side or between the two sides were computed as intraclass correlations which are measures of linear correlation when the two variables are interchangeable (i. e., the results for the two fascicles on each side could be interchanged since it is arbitrary which is labelled first and which is second).

\section{Results}

\section{Post-mortem stability of nerve morphometry (Table 1)}

Comparison of morphometric parameters in contralateral sural nerve specimens obtained pre- and post-mortem from three non-diabetic cadaveric organ donors revealed no systematic alteration in the first $6 \mathrm{~h}$ after death (Table 1).

Table 1. Pre- and post-mortem sural nerve morphometry in three normal control subjects

\begin{tabular}{|c|c|c|c|c|c|c|}
\hline \multirow[t]{2}{*}{ Variable } & \multicolumn{2}{|c|}{ Subject 1} & \multicolumn{2}{|c|}{ Subject 2} & \multicolumn{2}{|c|}{ Subject 3} \\
\hline & $\overline{\text { Pre }}$ & Post & $\overline{\text { Pre }}$ & Post & $\overline{\text { Pre }}$ & Post \\
\hline Fibre size $\left(\mu \mathrm{m}^{2}\right)$ & 34.1 & 35.6 & 34.5 & 33.4 & 40.1 & 41.4 \\
\hline Fibre density $\left(\# / \mathrm{mm}^{2}\right)$ & 7,253 & 7,155 & 8,267 & 8,483 & 8,981 & 9,144 \\
\hline Fibre occupancy (\%) & 26.2 & 25.5 & 27.9 & 28.3 & 37.1 & 37.9 \\
\hline Index of normality & 6,847 & 6,640 & 7,953 & 8,033 & 8,585 & 8,669 \\
\hline$\%$ Axo-glial & 4.9 & 5.4 & 6.9 & 8.3 & 4.1 & 3.8 \\
\hline$\%$ Normal & 94.4 & 92.8 & 96.2 & 94.7 & 95.6 & 94.8 \\
\hline$\%$ Swelling & 0.0 & 0.9 & 0.0 & 0.0 & 0.0 & 0.0 \\
\hline elination & 0.8 & 0.0 & 0.0 & 0.7 & 0.0 & 0.0 \\
\hline$\%$ Wrinkled & 1.7 & 0.9 & 1.3 & 1.3 & 0.7 & 1.2 \\
\hline$\%$ Intercalated & 0.0 & 0.0 & 0.7 & 0.0 & 1.5 & 0.0 \\
\hline$\%$ Wallerian & 0.8 & 0.9 & 0.0 & 1.3 & 0.7 & 0.6 \\
\hline \% Segmental & 0.0 & 0.9 & 0.0 & 1.3 & 0.7 & 0.6 \\
\hline$\%$ Regenerated & 1.7 & 2.8 & 1.3 & 0.7 & 0.7 & 2.5 \\
\hline
\end{tabular}




\section{Effect of diabetes on nerve fibre loss, atrophy and injury} (Table 2)

Means, SD and ranges for morphometric variables are presented in Table 2 for the diabetic cases and the nondiabetic control subjects. The $p$-values of the BehrensFisher $t$-test to compare the two group means and of Levene's test for the equality of the two variances are presented in Table 2. Attributes of nerve fibre damage were more evident in diabetic cases compared to nondiabetic control subjects. Fibre density, a measure of fibre loss, and mean fibre size and fibre occupancy, reflective of fibre loss and atrophy, had larger means in normal control subjects than in the diabetic cases but the diabetic cases exhibited larger variances. No differences in areas of examined fascicles could be demonstrated between fascicles of the same side, or between sides, or between control subjects and diabetic cases (Table 3 ). Index of normality and \% normal were also greater in normal control subjects than in the diabetic cases. The frequencies of four categories of abnormal nerve fibres (\% swelling, \% demyelinated, \% wrinkled and \% Wallerian) were greater in diabetic cases than in control subjects. Thus, sural nerve samples from diabetic autopsy cases unselected for clinical neuropathy demonstrated significant evidence of nerve fibre loss, atrophy and injury compared to control subjects.

The nerve-fibre damage as measured by differences between the diabetic and non-diabetic subjects in this study were qualitatively similar (i. e. differ in the same direction) to those previously reported for a somewhat younger group of diabetic patients with diagnosed polyneuropathy compared to their age-matched control subjects [29]. In the present study, the difference between the diabetic and non-diabetic subjects was somewhat less than that reported in the previous study for many of the individual morphometric parameters (e.g. fibre density, \% wrinkled, \% normal and \% axo-glial) [21], although the reduction in mean fibre size in the diabetic subjects was proportionately greater in the present study. This generally milder degree of nerve damage is in keeping with the fact that the present cases were unselected for the presence of diagnosed diabetic neuropathy.

\section{Effect of diabetes on the components of variation of morphometric variables}

The primary goal of this study was to analyse the components of variation of the morphometric attributes of fibre injury in diabetic neuropathy (i. e. how large was the in-

Table 2. Descriptive statistics for each morphometric variable by group

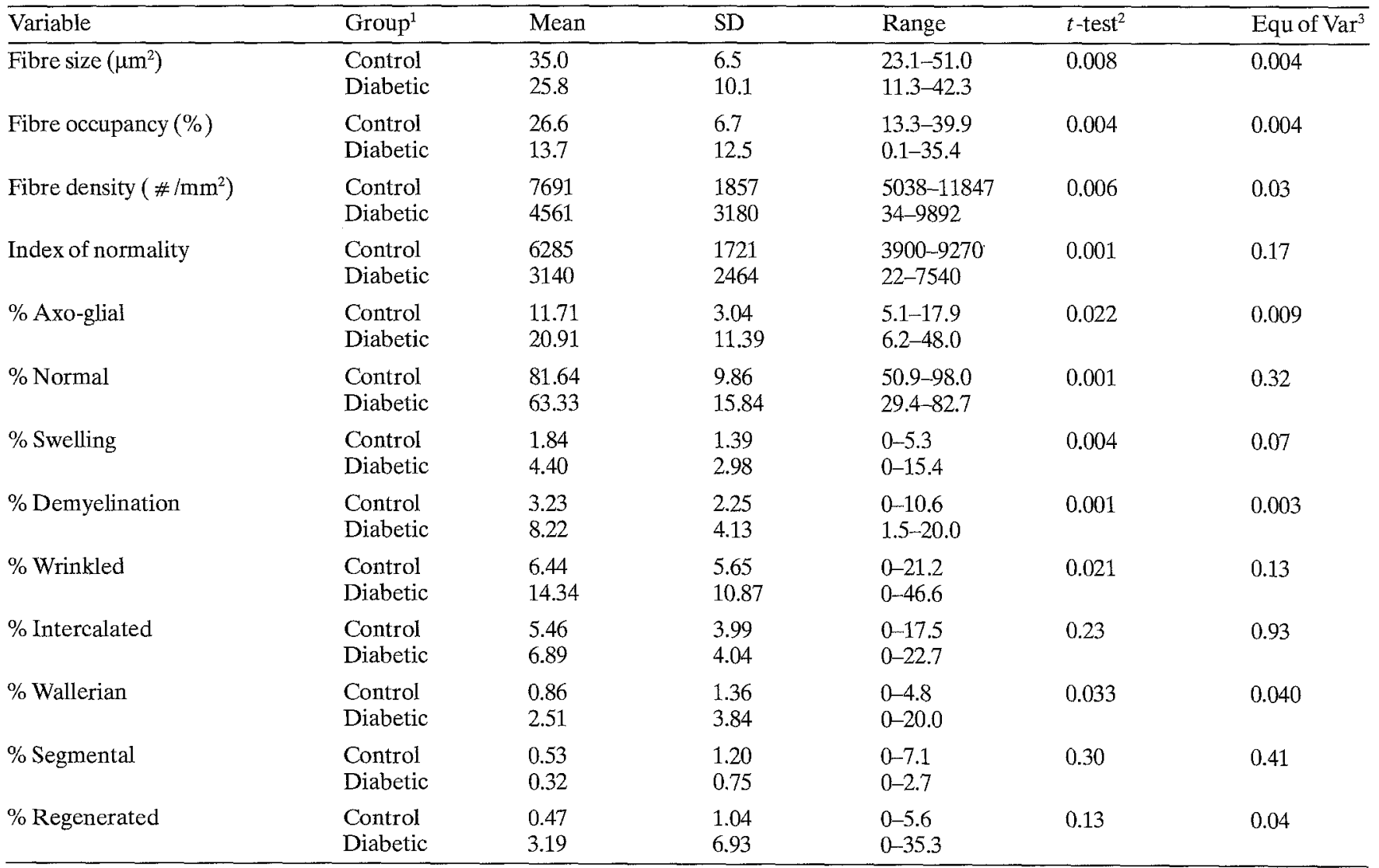

${ }^{1}$ There are 13 subjects per group, except that "\% axo-glial" is available for only 11 diabetic subjects.

${ }^{2}$ The column " $t$-test" contains $p$-values for the two-sample (Behrens-Fisher) $t$-test, and indicates the probability that the means of the control and diabetic groups could have differed by chance alone.

\footnotetext{
${ }^{3}$ The column "equ of var" contains $p$-values for the Levene-'s test of equality of variances and indicates the probability that the variances of the control and diabetic groups could have differed by chance alone. All $p$-values are two-tailed
} 
Table 3. Mean fascicular areas of the first and second fascicles of the left and right sural nerves from control subjects and diabetic patients ${ }^{\mathrm{a}}$

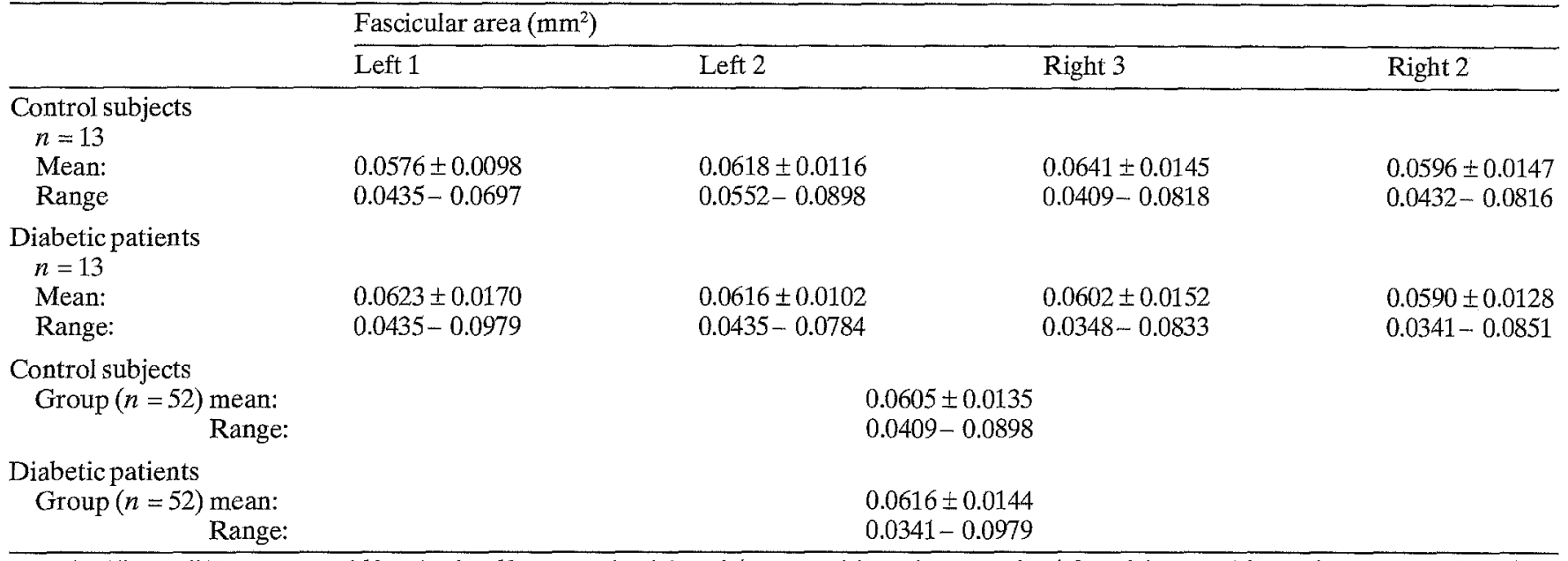

${ }^{a}$ No significant differences could be obtained between fascicles of the same side, or between fascicles of the two sides, or between fascicles from control subjects and diabetic patients

herent variation of the measurements and how these measures differed as a function of fascicle and side relative to differences between individuals). The components of variance were estimated from a two-way repeated measures analysis of variance (ANOVA) model fitted to the data for each variable where the factors were fascicle and side. If all the factors were assumed to be random effects, it was possible to estimate the variation due to the three factors. The estimates of the components of variance expressed as coefficients of variation (CV) are shown in Table 4.

Since each teased fibre frequency was based on counting the type of fibre abnormality among the $\sim 100$ fibres examined, it was possible to compute the theoretical variance due to counting a random set of fibres, which would represent a lower limit to the technical variation of the method. This lower limit for the standard deviation (SD) representing the technical error of the percent counts was approximated by the formula for a binomial variate, i.e., $\mathrm{SD}=100[\mathrm{p}(1-\mathrm{p}) / \mathrm{n}]^{1 / 2}$ and $\mathrm{CV}(\%)=100[(1-\mathrm{p}) /(\mathrm{np})]^{1 / 2}$ where $p$ is the proportion of the fibres and $n$ is the total number of fibres counted. For example, the mean of $\%$ normal was $72.5 \%$, with theoretical SD of $4.5 \%$ and a CV-err of $6.2 \%$. Since $6.2 \%$ is greater than the CV-err in Table 4, the variability was explained by the random process of choosing fibres to be counted. Other possible components of residual error would include heterogeneity within fascicles, etc.

A reproducible observation in an observation for which CV-subj > > CV-err, CV-fasc and CV-side. This pattern (a ratio of 5:1 for CV-subj divided by the largest of CV-err, CVfasc and CV-side) was observed for fibre size, density and occupancy, \% axo-glial, \% normal and index of normality. $\%$ Wrinkled had a ratio of 2:1 and other variables had ratios less than 1:1. For untreated diabetic subjects, the ratio for $\%$ regeneration was approximately $2: 1$, although a large change $(300 \%)$ in \% regeneration has been reported in diabetic subjects as a result of metabolic intervention, in which case this measure would also become highly reproducible due to the large anticipated increase [26].
As part of the results of the ANOVA, the effects of side and fascicle and their interaction were tested. Since these tests were performed for each line of Table 4 , a total of 117 tests were computed. Of these tests, only one test was significant at the $1 \%$ level of significance and another five at the $5 \%$ level; this is what would be expected by chance alone when this number of tests are performed.

Another way of evaluating the consistency of the results between fascicles and/or sides is to compute the correlation between sides or between fascicles. The intraclass correlation coefficients are presented in Table 5. A high correlation implies good agreement between the two fascicles or sides. Zero indicates that the minimum correlation was negative. The variables fibre size, fibre occupancy, fibre density, \% axo-glial, \% normal and index of normality were relatively consistent between fascicles and between sides, and thus constituted informative parameters in the sense that they reflected the degree of fibre damage for an individual subject. In contrast, fibre categories that appeared infrequently had low correlations, i. e. exhibited poor agreement between biopsies. These results supported those of the ANOVA. By these criteria, six parameters, fibre size, fibre occupancy, fibre density, $\%$ axo-glial, \% normal and index of normality, constituted logical candidates for end-points in cross-sectional or longitudinal studies of peripheral nerve damage in diabetes. In addition, \% regenerated constituted an informative parameter under conditions when regeneration is substantially increased, for example by specific intervention such as ARI therapy [26].

\section{Discussion}

These studies were not intended to explore the fundamental morphometric basis of diabetic neuropathy. Rather they employed autopsy material as a convenient model in which to examine the extent to which sampling errors and/or intrinsic variability might limit the sensitivity and specificity of fascicular sural nerve biopsies as quantita- 
Table 4. Coefficients of variation of the morphometric measurements by group

\begin{tabular}{|c|c|c|c|c|c|c|}
\hline Variable & Gro & Mean & $\begin{array}{l}\text { CV- } \\
\text { Err }^{\mathrm{b}}\end{array}$ & $\begin{array}{l}\mathrm{CV}- \\
\text { Fasc }^{\mathrm{b}}\end{array}$ & $\begin{array}{l}\text { CV- } \\
\text { Side }^{b}\end{array}$ & $\begin{array}{l}\text { CV- } \\
\text { Betw }^{b}\end{array}$ \\
\hline $\mathrm{ze}(\mu$ & $\begin{array}{l}\text { All } \\
\text { Control } \\
\text { Diabetic }\end{array}$ & $\begin{array}{l}30.40 \\
35.04 \\
25.75\end{array}$ & $\begin{array}{r}10 \% \\
6 \% \\
15 \%\end{array}$ & $\begin{array}{l}4 \% \\
5 \% \\
0 \%\end{array}$ & $\begin{array}{l}0 \% \\
0 \% \\
0 \%\end{array}$ & $\begin{array}{l}30 \% \\
17 \% \\
37 \%\end{array}$ \\
\hline $\begin{array}{l}\text { Fibre density } \\
\left(\# / \mathrm{mm}^{2}\right)\end{array}$ & $\begin{array}{l}\text { All } \\
\text { Control } \\
\text { Diabetic }\end{array}$ & $\begin{array}{l}6126 \\
7691 \\
4561\end{array}$ & $\begin{array}{r}9 \% \\
8 \% \\
11 \%\end{array}$ & $\begin{array}{l}0 \% \\
0 \% \\
3 \%\end{array}$ & $\begin{array}{l}0 \% \\
0 \% \\
0 \%\end{array}$ & $\begin{array}{l}48 \% \\
23 \% \\
69 \%\end{array}$ \\
\hline $\begin{array}{l}\text { Fibre occupancy } \\
(\%)\end{array}$ & $\begin{array}{l}\text { All } \\
\text { Control } \\
\text { Diabetic }\end{array}$ & $\begin{array}{l}20.15 \\
26.59 \\
13.72\end{array}$ & $\begin{array}{r}9 \% \\
7 \% \\
11 \%\end{array}$ & $\begin{array}{l}5 \% \\
4 \% \\
4 \%\end{array}$ & $\begin{array}{l}4 \% \\
3 \% \\
4 \%\end{array}$ & $\begin{array}{l}58 \% \\
23 \% \\
90 \%\end{array}$ \\
\hline Index of normality & $\begin{array}{l}\text { All } \\
\text { Control } \\
\text { Diabetic }\end{array}$ & $\begin{array}{l}4712 \\
6285 \\
3140\end{array}$ & $\begin{array}{l}11 \% \\
10 \% \\
13 \%\end{array}$ & $\begin{array}{l}3 \% \\
2 \% \\
5 \%\end{array}$ & $\begin{array}{l}0 \% \\
0 \% \\
0 \%\end{array}$ & $\begin{array}{l}55 \% \\
26 \% \\
77 \%\end{array}$ \\
\hline$\%$ Axo-glial & $\begin{array}{l}\text { All } \\
\text { Control } \\
\text { Diabetic }\end{array}$ & $\begin{array}{l}15.93 \\
11.71 \\
20.91\end{array}$ & $\begin{array}{r}10 \% \\
12 \% \\
9 \%\end{array}$ & $\begin{array}{l}3 \% \\
0 \% \\
5 \%\end{array}$ & $\begin{array}{l}8 \% \\
0 \% \\
9 \%\end{array}$ & $\begin{array}{l}56 \% \\
24 \% \\
53 \%\end{array}$ \\
\hline$\%$ Normal & $\begin{array}{l}\text { All } \\
\text { Control } \\
\text { Diabetic }\end{array}$ & $\begin{array}{l}72.48 \\
81.64 \\
63.33\end{array}$ & $\begin{array}{l}4 \% \\
4 \% \\
5 \%\end{array}$ & $\begin{array}{l}3 \% \\
3 \% \\
3 \%\end{array}$ & $\begin{array}{l}0 \% \\
0 \% \\
2 \%\end{array}$ & $\begin{array}{l}21 \% \\
11 \% \\
23 \%\end{array}$ \\
\hline$\%$ Swelling & $\begin{array}{l}\text { All } \\
\text { Control } \\
\text { Diabetic }\end{array}$ & $\begin{array}{l}3.12 \\
1.84 \\
4.40\end{array}$ & $\begin{array}{l}55 \% \\
63 \% \\
49 \%\end{array}$ & $\begin{array}{r}0 \% \\
34 \% \\
0 \%\end{array}$ & $\begin{array}{l}0 \% \\
0 \% \\
0 \%\end{array}$ & $\begin{array}{l}67 \% \\
22 \% \\
52 \%\end{array}$ \\
\hline$\% \mathrm{De}$ & $\begin{array}{l}\text { All } \\
\text { Control } \\
\text { Diabetic }\end{array}$ & $\begin{array}{l}5.72 \\
3.23 \\
8.22\end{array}$ & $\begin{array}{l}48 \% \\
55 \% \\
42 \%\end{array}$ & $\begin{array}{l}0 \% \\
0 \% \\
0 \%\end{array}$ & $\begin{array}{r}13 \% \\
38 \% \\
0 \%\end{array}$ & $\begin{array}{l}56 \% \\
26 \% \\
33 \%\end{array}$ \\
\hline \% Wrinkled & $\begin{array}{l}\text { All } \\
\text { Control } \\
\text { Diabetic }\end{array}$ & $\begin{array}{r}10.39 \\
6.44 \\
14.34\end{array}$ & $\begin{array}{l}35 \% \\
42 \% \\
30 \%\end{array}$ & $\begin{array}{r}26 \% \\
0 \% \\
28 \%\end{array}$ & $\begin{array}{r}0 \% \\
14 \% \\
0 \%\end{array}$ & $\begin{array}{l}80 \% \\
77 \% \\
64 \%\end{array}$ \\
\hline$\%$ Intercalated & $\begin{array}{l}\text { All } \\
\text { Control } \\
\text { Diabetic }\end{array}$ & $\begin{array}{l}6.17 \\
5.46 \\
6.89\end{array}$ & $\begin{array}{l}45 \% \\
47 \% \\
43 \%\end{array}$ & $\begin{array}{l}19 \% \\
24 \% \\
15 \%\end{array}$ & $\begin{array}{r}22 \% \\
35 \% \\
4 \%\end{array}$ & $\begin{array}{l}38 \% \\
35 \% \\
38 \%\end{array}$ \\
\hline$\%$ Wallerian & $\begin{array}{l}\text { All } \\
\text { Control } \\
\text { Diabetic }\end{array}$ & $\begin{array}{l}1.69 \\
0.86 \\
2.51\end{array}$ & $\begin{array}{l}92 \% \\
99 \% \\
80 \%\end{array}$ & $\begin{array}{r}154 \% \\
90 \% \\
143 \%\end{array}$ & $\begin{array}{r}0 \% \\
28 \% \\
0 \%\end{array}$ & $\begin{array}{r}0 \% \\
31 \% \\
0 \%\end{array}$ \\
\hline$\%$ Segmental & $\begin{array}{l}\text { All } \\
\text { Control } \\
\text { Diabetic }\end{array}$ & $\begin{array}{l}0.42 \\
0.53 \\
0.32\end{array}$ & $\begin{array}{l}195 \% \\
195 \% \\
173 \%\end{array}$ & $\begin{array}{r}104 \% \\
118 \% \\
0 \%\end{array}$ & $\begin{array}{r}35 \% \\
0 \% \\
181 \%\end{array}$ & $\begin{array}{l}0 \% \\
0 \% \\
0 \%\end{array}$ \\
\hline 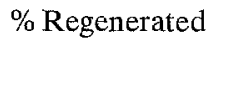 & $\begin{array}{l}\text { All } \\
\text { Control } \\
\text { Diabetic }\end{array}$ & $\begin{array}{l}1.83 \\
0.47 \\
3.19\end{array}$ & $\begin{array}{r}83 \% \\
197 \% \\
61 \%\end{array}$ & $\begin{array}{l}82 \% \\
88 \% \\
65 \%\end{array}$ & $\begin{array}{r}108 \% \\
0 \% \\
89 \%\end{array}$ & $\begin{array}{r}219 \% \\
80 \% \\
170 \%\end{array}$ \\
\hline
\end{tabular}

a "All" refers to the combined total of 13 control and 13 diabetic subjects, except that data on \% axo-glial was available for only 11 of the 13 diabetic subjects.

${ }^{b} \mathrm{CV}$ 's are expressed as percentages of the mean
Table 5. Intraclass correlation between ipsilateral fascicles and between sides for all subjects

\begin{tabular}{llll}
\hline \multirow{2}{*}{ Variable } & \multicolumn{2}{l}{ Within sides } & \multirow{2}{*}{ Between sides } \\
\cline { 2 - 3 } & Left & Right & \\
\hline Fibre size & 0.90 & 0.85 & 0.96 \\
Fibre density & 0.97 & 0.95 & 0.99 \\
Fibre occupancy & 0.97 & 0.96 & 0.97 \\
Index of normality & 0.96 & 0.95 & 0.99 \\
\% Axo-glial & 0.97 & 0.95 & 0.96 \\
\% Normal & 0.93 & 0.94 & 0.95 \\
\% Swelling & 0.58 & 0.68 & 0.79 \\
\% Demyelination & 0.67 & 0.66 & 0.69 \\
\% Wrinkled & 0.66 & 0.84 & 0.92 \\
\% Intercalated & 0.13 & 0.59 & 0.39 \\
\% Wallerian & 0 & 0 & 0.70 \\
\% Segmental & 0.02 & 0.19 & 0 \\
\% Regenerated & 0.94 & 0.35 & 0.68 \\
\hline
\end{tabular}

tive indicators of the severity of sural nerve damage in clinical studies of diabetic neuropathy. These observations demonstrate that certain morphological hallmarks of nerve fibre damage in diabetes and in diabetic neuropathy can be reliably assessed and quantitated in single samples of sural nerve, and that the sampling errors are small compared to the changes produced by diabetes. They also suggest that the morphometric data obtained from a single fascicle are representative of those for the whole sural nerve, and that the variation between contralateral sural nerves is small. Although these studies focused on sural nerve samples from cadavers, they are readily extrapolated to sural nerve biopsies from living patients because the abnormalities associated with diabetes are qualitatively similar to those in nerve biopsies from neuropathic diabetic patients, and because these morphometric parameters including \%axo-glial and $\%$ wrinkled are stable for at least $6 \mathrm{~h}$ after death [21]. However, because of the invasive nature of the sural nerve biopsy procedure and a small risk of persisting pain or paraesthesia post-operatively, it should not be regarded as a routine diagnostic technique, but merely be limited to detailed assessments of drug efficacy in clinical trials and to comprehensive well-designed cross-sectional clinical investigations intended to explore the natural history of the disease. Furthermore fibre density and occupancy can be regarded as reliable measures of fibre loss, since fascicular area from which these measures are partially derived, was unchanged between fascicles of the same

Table 6. Estimates of coefficients of variation (CV's) for the computation of sample sizes for clinical trials in diabetic subjects employing sural nerve morphometry

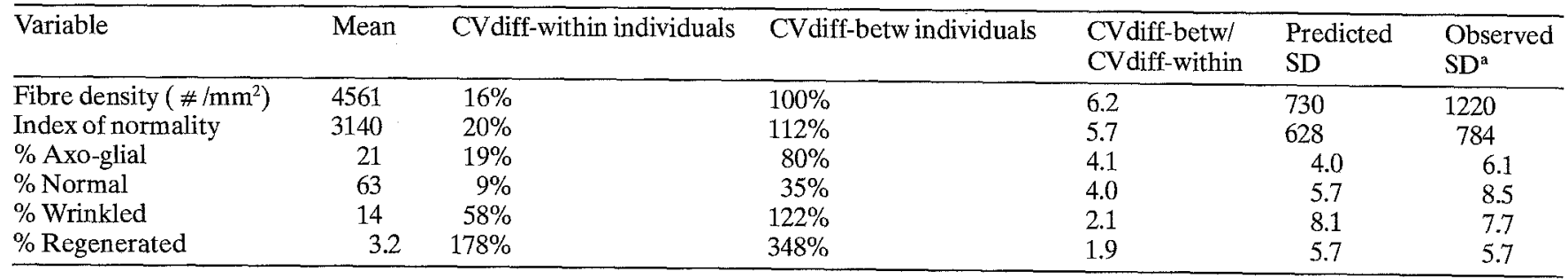

${ }^{a}$ Based on published aldose reductase inhibitor trial using serial nerve biopsies [26] 
side, between sides or between control subjects and diabetic cases. Thus, reliable estimates of nerve fibre loss (fibre density and occupancy), atrophy (mean fibre size, $\%$ wrinkling and fibre occupancy), injury (\% normal and $\%$ axo-glial), and overall damage (index of normality) can be used to measure severity, progression and/or treatment response in patients with diabetes and/or diabetic neuropathy. Furthermore, nerve fibre regeneration can be reliably assessed when \% regeneration is increased in response to therapy [26].

The estimates of the CV's can be used to define the sample size of a study of the natural progression of the disease. In such a study the CV's represent the anticipated variability between two biopsies when no changes are expected. The $\mathrm{CV}$ of a difference between two biopsies within the same individual at different time points $(\mathrm{CV}$ diff-within) is computed as the square root of $2(\mathrm{CV}$ $\mathrm{err}^{2}+\mathrm{CV}$-fasc ${ }^{2}+\mathrm{CV}$-side $\left.{ }^{2}\right)$. The CV of a difference between two individuals (CV diff-betw) would be computed similarly but would also include in the summation the $\mathrm{CV}$ subj ${ }^{2}$.

To show a change of one SD in paired biopsies from the same individual at different time points when using a paired $t$-test (i.e., a change equal to $\mathrm{CV}$ diff-within), 10 subjects are necessary to achieve $80 \%$ power using a two-sided 5\% level of significance. To achieve the same power using a case-control design where pairs of subjects at presumably the same stage of disease would be randomly assigned to undergo biopsy at one of two time points would require a change equal to the $\mathrm{CV}$ diff-betw to achieve the same power. The squares of the ratios CV diff-betw and CV diff-within represent the increase in sample size that would be needed if a case-control study design was used in place of a dual biopsy design. That is, the sample size would have to increase greatly if the same subjects are not biopsied twice to obtain longitudinal data reflecting disease progression.

Many studies require the comparison of a treatment to a placebo. Since not all subjects will react similarly to the treatment, it is necessary to include the variability of responses to the treatment in the calculation of the sample size. Although differences between the two biopsies from each subject are computed, the comparison of the differences between the two groups involves a between-subject component. When the SD obtained for the difference in the treated group (10 subjects) in a previous double biopsy study [26] is compared with the predicted SD-within from this study, the two SD's are very similar for several of the parameters, but for others there is a ratio of 1.5-2.0. For these parameters, it is necessary to adjust the sample size of the planned experiment to allow for this increased variability which may be due to a differential response to the treatment.

The design of therapeutic trials in complex chronic diseases is often severely limited by disease heterogeneity, chronicity, and irreversibility, as well as the lack of objective, quantitative, sensitive and reproducible measures to assess disease progression. Although a consensus conference suggested a combination of clinical and objective tests to diagnose and stage diabetic peripheral neuropathy [29], the sensitivity and reproducibility of this staging paradigm for therapeutic intervention trials was not addressed. Indeed, using acceptable norms of reproducibility [30], and minimal estimates for clinically significant changes [31] for vibratory perception threshold measurements, it has been estimated that hundreds of patients per group would be required to demonstrate with acceptable power a minimally clinically significant vibratory perception threshold response to metabolic intervention over a 12-month treatment trial [P. Sönksen, personal communication]. Although smaller sample sizes would possess adequate statistical power to document corresponding degrees of improvement in nerve conduction velocity [31, P.Sönksen, personal communication], the clinical relevance of such demonstrations [16] in the past has been questioned. In contrast, nerve fibre damage defines diabetic neuropathy, clearly distinguishing diabetic patients with neuropathy from non-diabetic subjects and from non-neuropathic diabetic patients [32]. Nerve fibre damage correlates with clinical neuropathic status and nerve function in diabetic neuropathy $[3,7,25,26]$, and is generally accepted to be the underlying cause of the common clinical syndromes of diabetic peripheral polyneuropathy $[1,3,7,19,20,21,25,26,32]$; hence its overall clinical relevance is unquestioned. This report demonstrates that the major morphometric parameters of the three cardinal elements of nerve fibre damage in diabetes, nerve fibre loss, atrophy and injury, can be reproducibly and sensitively measured in sural nerve biopsies from small numbers of subjects, suggesting that quantitative morphometric analysis of sural nerve biopsies constitutes a sensitive, reproducible and informative end-point for clinical studies of diabetic neuropathy.

Acknowledgements. The authors wish to acknowledge the assistance of the Imaging and Biostatistics Cores of the Michigan Diabetes Research and Training Center. These studies were supported in part by grants to Dr. A.A.F. Sima from ICI Pharmaceuticals, Wilmington, DE and the Medical Research Council of Canada.

\section{References}

1. Greene DA, Sima AAF, Albers JW, Pfeifer MA (1990) Pathophysiology of diabetic neuropathy. In: Rifkin $H$, Porte D (eds) Ellenberg and Rifkin's diabetes mellitus, 4th edn. Elsevier, Amsterdam, pp 710-755

2. Sima AAF, Greene DA (1991) Sural nerve fiber density and normality predict clinical sensory deficits and electrophysiology in chronic diabetic neuropathy. Diabetes 40:554 A (Abstract)

3. Britland ST, Young RJ, Sharma AK, Clarke BF (1990) Association of painful and painless diabetic polyneuropathy with different patterns of nerve fiber degeneration and regeneration. Diabetes 39: 898-908

4. Dyck PJ, Karnes J, O'Brien PC (1987) Detection of thresholds of cutaneous sensation. In: Dyck PJ, Thomas PK, Asbury AK, Winegrad AI, Porte D, Jr (eds) Diabetic neuropathy. W.B.Saunders, Philadelphia, pp 107-121

5. Maser RE, Nielsen VK, Bass EB, et al. (1989) Measuring diabetic neuropathy: assessment and comparison of clinical examination and quantitative sensory testing. Diab Care 12:270275

6. Thiele K, Stålberg E (1975) Single fiber EMG findings in polyneuropathies of different etiology. $J$ Neurol Neurosurg Neuropsychiatry 38: 881-887 
7. Behse F, Buchthal F, Carlsen F (1977) Nerve biopsy and conduction studies in diabetic neuropathy. $\mathbf{J}$ Neurol Neurosurg Psychiatry 40: 1072-1082

8. Gregersen $G$ (1968) Variations in motor conduction velocity produced by acute changes of the metabolic state in diabetic patients. Diabetologia 4: 273-277

9. Ward JD, Barnes CG, Fisher DJ, Jessop JD, Baker RW (1971) Improvement in nerve conduction following treatment in newly diagnosed diabetics. Lancet I: $428-430$

10. Troni W, Carta Q, Cantello R, Caselle MT, Rainero I (1984) Peripheral nerve function and metabolic control in diabetes mellitus. Ann Neurol 16: 178-183

11. Graf RJ, Halter JB, Pfeifer MD, et al. (1981) Glycemic control and nerve conduction abnormalities in noninsulin-dependent diabetic subjects. Ann Intern Med 94:307-311

12. Holman RR, Dornan TL, Mayon-White VM, et al. (1983) Prevention of deterioration of renal and sensory-nerve function by more intensive management of insulin-dependent diabetic patients. A two-year randomized prospective study. Lancet I: 204-208

13. Pietri A, Ehle A, Raskin P (1980) Changes in nerve conduction velocity after six weeks of glycoregulation with portable insulin infusion pumps. Diabetes 29: 668-671

14. Service FJ, Rizza RA, Daube JR, O'Brien PC, Dyck PJ (1985) Near normoglycaemia improved nerve conduction and vibration sensation in diabetic neuropathy. Diabetologia 28: 722-727

15. Steno Study Group (1982) Effect of 6 months strict metabolic control on eye and kidney function in insulin-dependent diabetes with background retinopathy. Lancet I: 121-124

16. Judzewitsch RG, Jaspan JB, Polonsky KS, et al. (1983) Aldose reductase inhibition improves nerve conduction velocity in diabetic patients. N Engl J Med 308: 119-125

17. Daube JR (1987) Electrophysiologic testing in diabetic neuropathy. In: Dyck PJ, Thomas PK, Asbury AK, Winegrad AI, Porte D, Jr (eds) Diabetic neuropathy. W.B.Saunders, Philadelphia, pp 162-176

18. Greene DA (1987) Metabolic control. In: Dyck PJ, Thomas PK, Asbury AK, Winegrad AI, Porte D, Jr (eds) Diabetic neuropathy. W.B.Saunders, Philadelphia, pp 177-187

19. Dyck PJ, Karnes JL, Daube J, O'Brien P, Service FJ (1985) Clini$\mathrm{cal}$ and neuropathologic criteria for the diagnosis and staging of diabetic polyneuropathy. Brain 108: $861-880$

20. Dyck PJ, Lais A, Karnes JL, O'Brien P, Rizza R (1986) Fiber loss is primary and multifocal in sural nerves in diabetic polyneuropathy. Ann Neurol 19: 425-439

21. Sima AAF, Nathaniel V, Bril V, McEwen TAJ, Greene DA (1988) Histopathological heterogeneity of neuropathy in insulindependent and non-insulin-dependent diabetes, and demonstration of axo-glial dysjunction in human diabetic neuropathy. J Clin Invest 81:349-364
22. Sima AAF, Lattimer SA, Yagihashi S, Greene DA (1986) 'Axoglial dysjunction' a novel structural lesion that accounts for poorly-reversible slowing of nerve conduction in the spontaneously diabetic BB-rat. J Clin Invest 77: 474-484

23. Sima AAF, Brismar T (1985) Reversible diabetic nerve dysfunction. Structural correlates to electrophysiological abnormalities. Ann Neurol 18: 21-29

24. Brismar T, Sima AAF, Greene DA (1987) Reversible and irreversible nodal dysfunction in diabetic neuropathy. Ann Neurol 21: 504-507

25. Sima AAF, Greene DA, Sorbinil and Tolrestat Neuropathy Study Groups (1991) Sural nerve fiber density and normality predict clinical sensory deficits and electrophysiology in chronic diabetic neuropathy. IDF-Satellite Symposium on Diabetic Neuropathy, New York, NY (Abstract)

26. Sima AAF, Bril V, Nathaniel V, et al. (1988) Regeneration and repair of myelinated fibers in sural nerve biopsies from patients with diabetic neuropathy treated with sorbinil, an investigational aldose reductase inhibitor. $\mathrm{N}$ Engl J Med 319: 548-555

27. Pfeifer MA, Porte D, Bril V, et al. and the Sorbinil Neuropathy Study Group (1989) Clinical response to sorbinil treatment in diabetic neuropathy. Diabetes 38: 14 (Abstract)

28. Boulton AJM, Levis S, Comstock JA (1990) A multicentre trial of the aldose-reductase inhibitor, tolrestat, in patients with symptomatic diabetic neuropathy. Diabetologia 33: 431-437

29. American Diabetes Association (1988) Report and recommendations of the San Antonio conference on diabetic neuropathy. Diabetes 37: 1000-1004

30. Dyck PJ, Busek W, Spring EM, et al. (1987) Vibratory and cooling detection thresholds compared with other tests in diagnosing and staging diabetic neuropathy. Diab Care 10: 432-440

31. Dyck P, O'Brien PC (1989) Meaningful degrees of prevention or improvement of nerve conduction in controlled clinical trials of diabetic neuropathy. Diab Care 12: 649-652

32. Dyck PJ, Karnes J, O'Brien PC (1987) Diagnosis, staging, and classification of diabetic neuropathy and associations with other complications. In: Dyck PJ, Thomas PK, Asbury AK, Winegrad AI, Porte D, Jr (eds) Diabetic neuropathy. W.B. Saunders, Philadelphia, pp 36-44

Received: 16 September 1991

and in revised form: 29 January 1992

Dr. A. A. F.Sima

Michigan Diabetes Research and Training Center

University of Michigan

1331 E. Ann St.

Ann Arbor, MI 48109-0580

USA 